\title{
Monthly trends of methane emissions in Los Angeles from 2011 to 2015 inferred by CLARS-FTS observations
}

\author{
Clare K. Wong ${ }^{1,2, a}$, Thomas J. Pongetti ${ }^{1}$, Tom Oda ${ }^{3,4}$, Preeti Rao ${ }^{1}$, Kevin R. Gurney ${ }^{5}$, Sally Newman $^{2}$, \\ Riley M. Duren ${ }^{1}$, Charles E. Miller ${ }^{1}$, Yuk L. Yung ${ }^{2}$, and Stanley P. Sander ${ }^{1}$ \\ ${ }^{1}$ NASA Jet Propulsion Laboratory, California Institute of Technology, Pasadena, California, USA \\ ${ }^{2}$ Division of Geological and Planetary Sciences, California Institute of Technology, Pasadena, California, USA \\ ${ }^{3}$ Goddard Earth Sciences Technology and Research, Universities Space Research Association, Columbia, Maryland, USA \\ ${ }^{4}$ Global Modeling and Assimilation Office, NASA Goddard Space Flight Center, Greenbelt, Maryland, USA \\ ${ }^{5}$ School of Life Sciences, Arizona State University, Tempe, Arizona, USA \\ ${ }^{a}$ currently at: California State University, Northridge, California, USA
}

Correspondence to: Clare K. Wong (wclare@gmail.com, clare.wong@csun.edu)

Received: 16 March 2016 - Published in Atmos. Chem. Phys. Discuss.: 29 April 2016

Revised: 6 September 2016 - Accepted: 10 September 2016 - Published: 26 October 2016

\begin{abstract}
This paper presents an analysis of methane emissions from the Los Angeles Basin at monthly timescales across a 4-year time period - from September 2011 to August 2015. Using observations acquired by a ground-based nearinfrared remote sensing instrument on Mount Wilson, California, combined with atmospheric $\mathrm{CH}_{4}-\mathrm{CO}_{2}$ tracer-tracer correlations, we observed -18 to $+22 \%$ monthly variability in $\mathrm{CH}_{4}: \mathrm{CO}_{2}$ from the annual mean in the Los Angeles Basin. Top-down estimates of methane emissions for the basin also exhibit significant monthly variability ( -19 to $+31 \%$ from annual mean and a maximum month-to-month change of $47 \%$ ). During this period, methane emissions consistently peaked in the late summer/early fall and winter. The estimated annual methane emissions did not show a statistically significant trend over the 2011 to 2015 time period.
\end{abstract}

\section{Introduction}

Methane $\left(\mathrm{CH}_{4}\right)$ is a potent and newly regulated greenhouse gas in California. However, its emissions are poorly understood. In the South Coast Air Basin, which holds more than $43 \%$ of state's population, the annual methane emissions estimates based on atmospheric $\mathrm{CH}_{4}$ observations indicate that the bottom-up emission inventory was systematically underestimated by 30 to $>100 \%$ (Wong et al., 2015; Jeong et al., 2013; Peischl et al., 2013; Wennberg et al., 2012; Wunch et al., 2009; Wecht et al., 2014; Cui et al., 2015). Methane sources in the basin can be classified into two categories biogenic and thermogenic. Biogenic methane is emitted from anaerobic digestion of organic matter by bacteria in waste management facilities, and by cattle in dairy farms. Waste management facilities include landfills, wastewater treatment plants, and manure management facilities in dairy farms. Thermogenic methane emissions include natural sources, such as seeps and tar pits, and anthropogenic sources such as natural gas system leakage and gas/oil fields. Emissions from these sources are likely to have different seasonal patterns. Quantifying and tracking the seasonal variability will help to elucidate methane emissions and are essential for verifying emissions regulation and mitigation policies. However, most studies to date have been based on data from short-term measurement campaigns and have provided limited information on the temporal variability or trends of methane emissions in the basin (Peischl et al., 2013; Wecht et al., 2014; Cui et al., 2015; Wunch et al., 2009).

One commonly used approach to estimate $\mathrm{CH}_{4}$ emissions from atmospheric observations is the tracer-tracer correlation technique. This method uses the regression slopes between observed trace gas mixing ratios (e.g., $\mathrm{CH}_{4}: \mathrm{CO}_{2}$ or $\mathrm{CH}_{4}: \mathrm{CO}$ ) in the atmosphere to calculate $\mathrm{CH}_{4}$ emissions based on the more accurately known emissions of the correlate (e.g., $\mathrm{CO}_{2}$ or $\mathrm{CO}$ ). This method permits the derivation of the relative emissions of the two trace gases without the use 


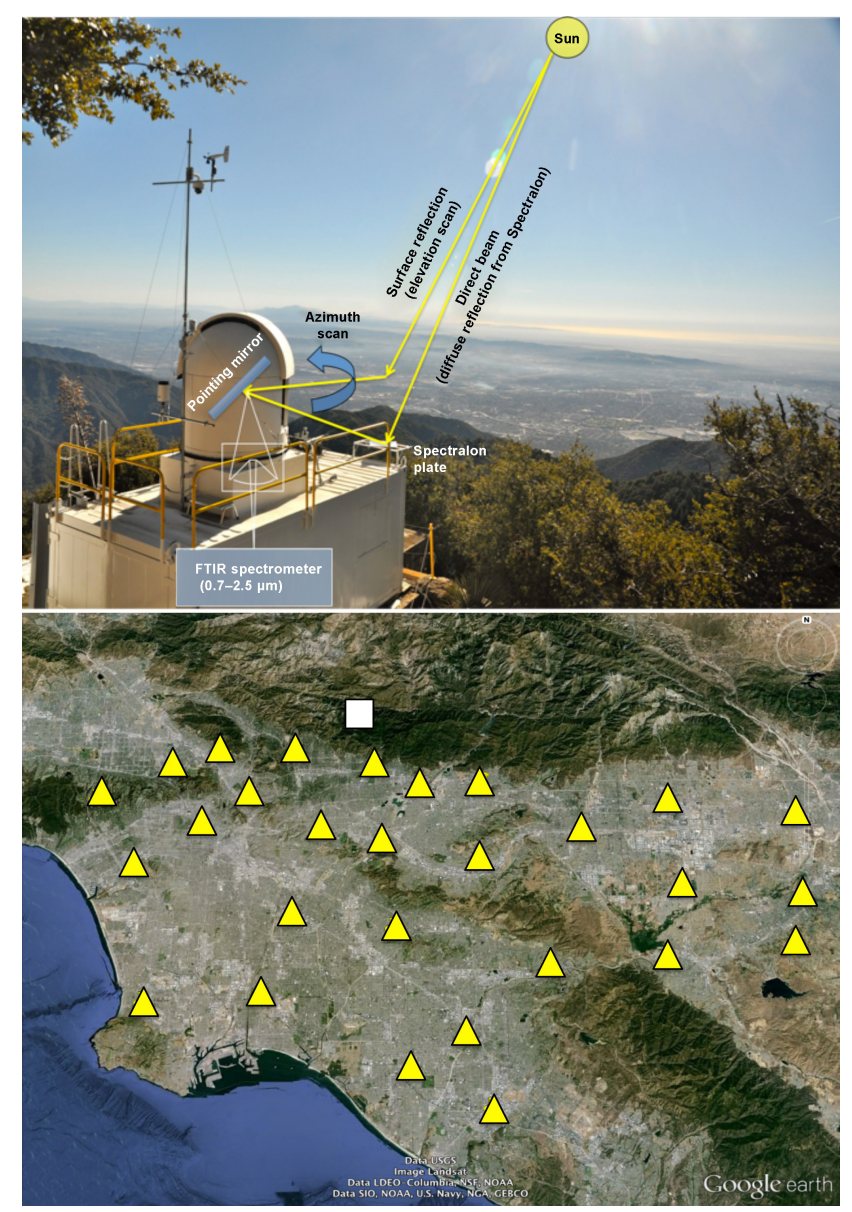

Figure 1. Top: CLARS facility located at $1.67 \mathrm{~km}$ above sea level on Mount Wilson, looking over the Los Angeles Basin. Optical paths from direct sun beam and basin surface reflection are shown as yellow lines. Bottom: location of 29 reflection points on Mount Wilson (white square) and in the basin (yellow triangles).

of transport models and does not require the sources to be colocated (Wong et al., 2015; Peischl et al., 2013; Wennberg et al., 2012; Hsu et al., 2010; Wunch et al., 2009). Based on in situ flask observations on Mount Wilson, Hsu et al. (2010) did not observe any seasonal variability in the $\mathrm{CH}_{4}$ : $\mathrm{CO}$ ratio from April 2007 to February 2008. Using column observations from the Total Carbon Column Observing Network (TCCON) in Pasadena, Wennberg et al. (2012) observed a $\pm 15 \%$ monthly variability in the $\mathrm{CH}_{4}$ : $\mathrm{CO}$ ratio between August 2007 to June 2008, but the monthly variability in methane emissions was not reported.

This paper presents the first study to quantify total methane emissions from an urban region at monthly intervals for an extended period of 4 years - from September 2011 to August 2015. Using a unique dataset of mountaintop remote sensing observations acquired with the California Laboratory of Atmospheric Remote Sensing Fourier Transform Spectrometer (CLARS-FTS; Wong et al., 2015; Fu et al., 2014), we have constructed a series of monthly $\mathrm{CH}_{4}: \mathrm{CO}_{2}$ tracertracer correlations to address the following questions:

- What is the monthly variability in methane emissions in the Los Angeles Basin?

- Is there a detectable year-to-year methane emissions change in the basin?

- What methane source(s) is (are) responsible for any observed temporal trends?

\section{Methods}

Since September 2011, continuous daytime ground-based remote sensing measurements of $\mathrm{CH}_{4}$ and $\mathrm{CO}_{2}$ have been acquired by a JPL-built Fourier transform spectrometer on Mount Wilson (Wong et al., 2015; Fu et al., 2014). The California Laboratory of Atmospheric Remote Sensing (CLARS) is located at an altitude of $1670 \mathrm{~m}$ above sea level with a panoramic view of the Los Angeles Basin (Fig. 1). CLARSFTS quantifies atmospheric column $\mathrm{CH}_{4}$ and $\mathrm{CO}_{2}$ using reflected sunlight in the near-infrared region. It operates in two measurement modes: Spectralon Viewing Observations (SVO) and Los Angeles Basin Surveys (LABS). In the SVO mode, the instrument quantifies the background tropospheric column $\mathrm{CH}_{4}$ and $\mathrm{CO}_{2}$ above the Los Angeles Basin by measuring reflectance from a Spectralon ${ }^{\circledR}$ plate located at the CLARS site. In the LABS mode, the instrument samples the basin slant column $\mathrm{CH}_{4}$ and $\mathrm{CO}_{2}$ by measuring the surface reflection from 28 geographical locations (or reflection points) in the basin (Fig. 1). We selected 28 reflection points to achieve an optimal spatial and temporal coverage of the Los Angeles Basin. The number, locations and repeat frequencies of the reflection points can be easily modified to meet specific measurement requirements. In each measurement cycle, we collect one set of LABS measurements and four SVO measurements. Four SVO measurements are performed per measurement cycle so that any variability in the background during each measurement cycle, which typically lasts for $90 \mathrm{~min}$, can be captured. There are five to eight measurement cycles per day, depending on the time of the year.

Based on the Beer-Lambert law, the slant column density (SCD) - the total number of absorbing molecules per unit area along the Sun-Earth-instrument optical path - is retrieved for $\mathrm{CH}_{4}$ at $1.67 \mu \mathrm{m}, \mathrm{CO}_{2}$ at $1.60 \mu \mathrm{m}$, and $\mathrm{O}_{2}$ at $1.27 \mu \mathrm{m}$ using a modified version of the GFIT algorithm developed at JPL (Fu et al., 2014; Wunch et al., 2011). The retrieved SCDs of $\mathrm{CH}_{4}$ and $\mathrm{CO}_{2}$ are then converted to slant column-averaged dry air mixing ratio, $\mathrm{XCH}_{4}$ and $X \mathrm{XO}_{2}$, by normalizing to the retrieved SCD of $\mathrm{O}_{2}\left(\mathrm{SCD}_{\mathrm{O}_{2}} ; \mathrm{Eq} .1\right)$.

$X \mathrm{GHG}=\frac{\mathrm{SCD}_{\mathrm{GHG}}}{\mathrm{SCD}_{\mathrm{O}_{2}}} \times 0.2095$

Individual retrievals are analyzed with multiple postprocessing filters to ensure data quality. Spectra are removed 


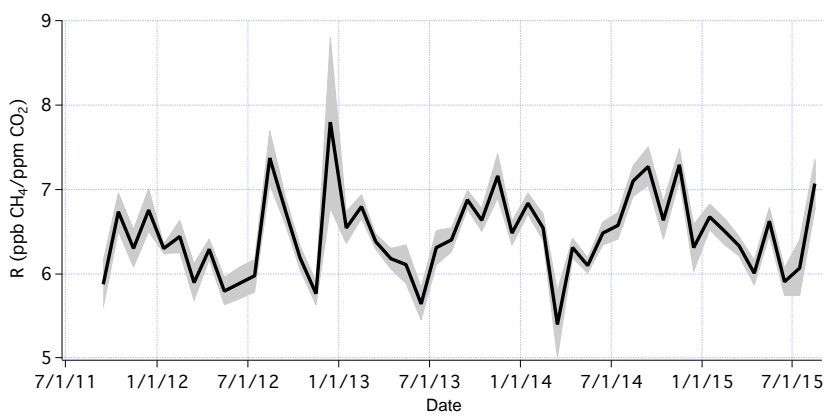

Figure 2. Time series of the Los Angeles Basin weighted-average monthly regression slopes of $\mathrm{XCH}_{4}(X S)-\mathrm{XCO}_{2}(X S)$ (in unit of $\mathrm{ppb} \mathrm{ppm}^{-1}$ ) and their uncertainties observed by the CLARS-FTS in the basin from September 2011 to May 2015. Uncertainties are $\pm 1 \sigma$ of the regression slopes.

when the residual root mean square errors of the fits to the GFIT radiative transfer model exceed a pre-defined threshold. These are usually associated with aerosols, high and low clouds, electrical or mechanical noise, and other transient behavior. Details about the CLARS-FTS design, data retrieval algorithm, and data-filtering process are described in Fu et al. (2014) and Wong et al. (2015).

Wong et al. (2015) mapped the spatial distribution of the $\mathrm{CH}_{4}: \mathrm{CO}_{2}$ ratio and derived an annual total $\mathrm{CH}_{4}$ emission for the basin, based on CLARS-FTS observations from 2011 to 2013. Here we used the same approach but focused on the temporal trend and quantified the monthly total $\mathrm{CH}_{4}$ emissions for the basin. Therefore, following Wong et al. (2015), we calculated the excess $X_{\mathrm{CH}_{4}}$ and $\mathrm{XCO}_{2}$, due to the emissions from the basin, by subtracting the corresponding SVO measurements from the LABS observations (Eq. 2).

$$
X \mathrm{GHG}_{X S}=X \mathrm{GHG}_{\mathrm{LABS}}-X \mathrm{GHG}_{\mathrm{SVO}}
$$

We then performed orthogonal distance regression (ODR) analyses of $X \mathrm{CH}_{4(X S)}$ and $X \mathrm{CO}_{2(X S)}$ for the 28 reflection points for each month starting from September 2011 to August 2015. An example of the scatter plot showing the correlation and the regression slope can be found in Fig. 1S of the supplemental material. To explore the overall monthly variability during this period, we calculated the weightedaverage regression slope among the 28 reflection points, $R$, using Eq. (3). In Eq. (3), $r_{i}$ stands for the regression slope for reflection point $i, w_{i}$ is the weight which is defined as the reciprocal of the square of the $1 \sigma$ uncertainty of the regression slope, $\sigma_{i}$.

$$
\left.R\right|_{\text {monthly }} ^{\text {CLARS }}=\frac{\sum_{i=1}^{i=28} r_{i} w_{i}}{\sum_{i=1}^{i=28} w_{i}},
$$

where

$$
w_{i}=\frac{1}{\sigma_{i}^{2}} \text {. }
$$

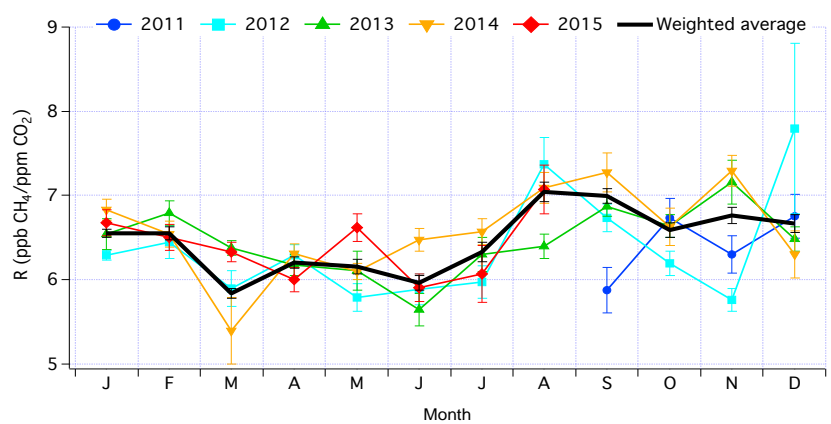

Figure 3. Monthly patterns of the Los Angeles Basin weightedaverage regression slopes of $X_{4} \mathrm{CH}_{4}(X S)-X \mathrm{CO}_{2(X S)}$ (in unit of $\mathrm{ppb} \mathrm{ppm}^{-1}$ ) and their uncertainties observed by the CLARS-FTS in the basin. Monthly trends are color-coded as follows: 2011 in blue, 2012 in cyan, 2013 in green, 2014 in orange, and 2015 in red. The monthly average ratio and its standard deviation over the entire observational period are shown in black.

\section{Results}

In this section, we describe the monthly and multi-year trends of the basin-average regression slope observed by CLARSFTS. Figure 2 shows the time series of the Los Angeles Basin weighted-average monthly $X \mathrm{CH}_{4(X S)}-X \mathrm{CO}_{2(X S)}$ regression slopes, $R$, and their uncertainties observed by the CLARS-FTS from September 2011 to May 2015. The $R$ values and their uncertainties are listed in Table $\mathrm{S} 1$ of the supplemental material. During this period, $R$ ranged from $5.4 \pm 0.4\left(\mathrm{ppm} \mathrm{CO}_{2}\right)^{-1}$ to $7.7 \pm 1.0 \mathrm{ppbCH}_{4}$ $(\mathrm{ppm} \mathrm{CO})^{-1}$ with an overall mean and standard deviation of $6.5 \pm 0.5 \mathrm{ppbCH}_{4}\left(\mathrm{ppmCO}_{2}\right)^{-1}$. This is consistent with previous atmospheric observations and their uncertainties: $7.8 \pm 0.8 \mathrm{ppb} \mathrm{CH}_{4}\left(\mathrm{ppm} \mathrm{CO}_{2}\right)^{-1}$ from TCCON in 2007$2008,6.7 \pm 0.6 \mathrm{ppbCH}_{4}\left(\mathrm{ppm} \mathrm{CO}_{2}\right)^{-1}$ from ARCTAS in 2008 , and $6.7 \pm 0.0 \mathrm{ppbCH}_{4}\left(\mathrm{ppm} \mathrm{CO}_{2}\right)^{-1}{ }^{1}$ from CalNex in 2010 (Wunch et al., 2009; Wennberg et al., 2012; Peischl et al., 2013). CLARS-FTS observations showed significant monthly fluctuations. The monthly variability in the slope was -8 to $+5 \%$ in $2011,-9$ to $+22 \%$ in $2012,-13$ to $+11 \%$ in $2013,-18$ to $+11 \%$ in 2014 , and -8 to $+11 \%$ in 2015. Monthly variability reported here spans the minimum and maximum deviations from the annual monthly mean for each year. Monthly variability for 2011 and 2015 was calculated based on partial annual data (that is, from September to December for 2011 and from January to August for 2015). In general, we observed peaks in late summer, fall, and winter: $R$ exceeded $7 \mathrm{ppbCH}_{4}\left(\mathrm{ppm} \mathrm{CO}_{2}\right)^{-1}$ in August 2012, December 2012, November 2013, August 2014, September 2014, November 2014, and August 2015. The smallest values of $R$ were observed in the spring and early summer. Typi-

\footnotetext{
${ }^{1}$ Peischl et al. (2013) reported $6.70 \pm 0.01 \mathrm{ppbCH}_{4}$ $(\mathrm{ppm} \mathrm{CO})^{-1}$ from CalNex in 2010.
} 


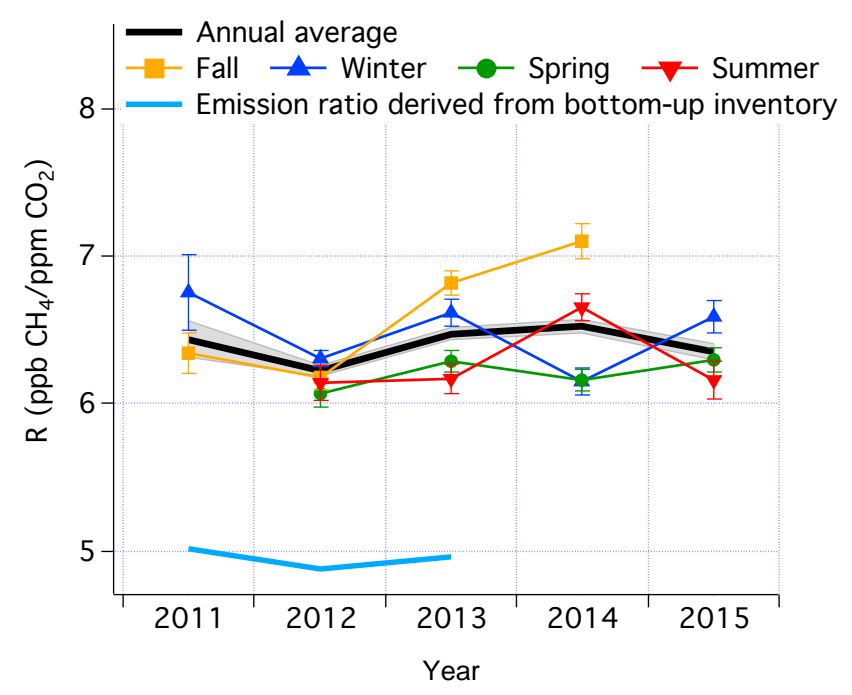

Figure 4. Interannual variability in $R$ (in unit of $\mathrm{ppbCH}_{4}$ $\left(\mathrm{ppm} \mathrm{CO}_{2}\right)^{-1}$ ) in fall (orange), winter (blue), spring (green), and summer (red) from 2011 to 2015 . The annual average ratio is shown in black. Also shown are the $\pm 1 \sigma$ uncertainties. Note that data for 2011 and 2015 are derived from partial annual observations (that is, September to December for 2011 and January to August for 2015). The $\mathrm{CH}_{4}: \mathrm{CO}_{2}$ ratio based on the population-scaled bottom-up emission inventory from the California Resources Board is shown in light blue (California Air Resources Board, 2013).

cally, $R$ dipped below $6 \mathrm{ppb} \mathrm{CH}_{4}\left(\mathrm{ppm} \mathrm{CO}_{2}\right)^{-1}$ in May-June, 2012, June 2013, and March 2013.

Figure 3 compares the year-to-year monthly values of $R$ to the 4-year mean values. The weighted 4-year mean values showed maxima in August and September, at $7.0 \mathrm{ppbCH}_{4}\left(\mathrm{ppmCO}_{2}\right)^{-1}$. Minima occurred in March, when the weighted monthly mean was $5.8 \mathrm{ppbCH}_{4}$ $(\mathrm{ppm} \mathrm{CO})^{-1}$. The fall peak was also observed by TCCON observations in Pasadena from 2007 to 2008 (Wennberg et al., 2012). However, no winter peak was observed in their study. CLARS observations showed multi-year variability for some months but not others. To better understand the seasonal year-to-year trends in $R$, we plotted the yearly trends for fall (September, October, and November), winter (December, January, and February), spring (March, April, and May) and summer (June, July, and August) in Fig. 4. A $15 \%$ increase in $R$ over Los Angeles was observed in the fall season over the last few years. $R$ increased from $6.2 \mathrm{ppb} \mathrm{CH}_{4}$ $\left(\mathrm{ppm} \mathrm{CO}_{2}\right)^{-1}$ in 2012 to $7.1 \mathrm{ppbCH}_{4}\left(\mathrm{ppm} \mathrm{CO}_{2}\right)^{-1}$ in 2014. This increasing trend was also observed in summer from 2012 to 2014. However, the summer value decreased again from 2014 to 2015 . No year-to-year change was observed in spring. In winter, there were some year-to-year changes but no obvious increasing or decreasing trend over the study period. The annual average $R$ value showed no significant trend and less than $4 \%$ year-to-year variability between 2011 and 2015.
For comparison, we also calculated the $\mathrm{CH}_{4}: \mathrm{CO}_{2}$ emission ratio based on a bottom-up emission inventory. The California Air Resources Board (CARB) reported statewide total emissions of $\mathrm{CH}_{4}$ and $\mathrm{CO}_{2}$ through 2013 (http: //www.arb.ca.gov/app/ghg/2000_2013/ghg_sector.php). For $\mathrm{CO}_{2}$, statewide emissions were 384,389 , and $387 \mathrm{TgCO}_{2}$ per year in 2011, 2012, and 2013, respectively. Following Wong et al. (2015), we downscaled the statewide $\mathrm{CO}_{2}$ emissions by fractional population ( $43 \%$ of state population) to obtain 165,167 , and $166 \mathrm{Tg} \mathrm{CO}_{2}$ per year in 2011,2012 , and 2013, respectively, for emissions from the South Coast Air Basin. For $\mathrm{CH}_{4}$, bottom-up emissions of 1629, 1636, and $1644 \mathrm{Gg} \mathrm{CH}_{4}$ per year were reported by CARB in 2011, 2012, and 2013, respectively. Following the approach used by Wong et al. (2015), we estimated the emissions from the South Coast Air Basin by subtracting the agriculture and forestry emissions from the total emissions and then apportioning the emissions by population. This gave us emissions of 301,297 and $300 \mathrm{Gg} \mathrm{CH}_{4}$ per year in the South Coast Air Basin from 2011 to 2013. The bottom-up estimate of $R$, the $\mathrm{CH}_{4} / \mathrm{CO}_{2}$ emission ratio, was calculated from Eq. (5), where $\left.E_{\mathrm{CH}_{4}}\right|_{\text {annual }}$ is is the downscaled CARB annual total $\mathrm{CH}_{4}$ emissions, $\left.E_{\mathrm{CO}_{2}}\right|_{\text {annual }} ^{\text {inventory }}$ is the downscaled CARB annual total $\mathrm{CO}_{2}$ emissions, and $\frac{\mathrm{MW}_{\mathrm{CO}_{2}}}{\mathrm{MW}_{\mathrm{CH}_{4}}}$ is the ratio of the molecular weights of $\mathrm{CH}_{4}$ and $\mathrm{CO}_{2}$ (that is, $\frac{44 \mathrm{gCO}_{2} / \text { mole }}{16 \mathrm{gCH}_{4} / \mathrm{mole}}$ ).

$R_{\text {annual }}^{\text {inventory }}=\frac{\left.E_{\mathrm{CH}_{4}}\right|_{\text {annual }} ^{\text {inventory }}}{\left.E_{\mathrm{CO}_{2}}\right|_{\text {annual }} ^{\text {inventory }}} \times \frac{\mathrm{MW}_{\mathrm{CO}_{2}}}{\mathrm{MW}_{\mathrm{CH}_{4}}}$

Using the downscaled CARB emission estimates for the South Coast Air Basin yields annual $R$ values of 5.0, 4.9, and $5.0 \mathrm{ppbCH}_{4}\left(\mathrm{ppm} \mathrm{CO}_{2}\right)^{-1}$ for 2011, 2012, and 2013 , respectively. Figure 4 shows the annual $R$ values determined from CLARS observations. CLARS annual $R$ values were $6.4 \pm 0.1\left(\mathrm{ppm} \mathrm{CO}_{2}\right)^{-1}, 6.2 \pm 0.1$ $\left(\mathrm{ppmCO}_{2}\right)^{-1}, 6.5 \pm\left(\mathrm{ppmCO}_{2}\right)^{-1}, 6.5 \pm 0.1\left(\mathrm{ppm} \mathrm{CO}_{2}\right)^{-1}$, and $6.4 \pm 0.1 \mathrm{ppbCH}_{4}\left(\mathrm{ppmCO}_{2}\right)^{-1}$ in $2011,2012,2013$, 2014 , and 2015, respectively. The inventory-based $R$ value systematically underestimated the observed annual $R$ values by about 20 to $25 \%$ during the time period from 2011 to 2013.

\section{Discussion}

We can rearrange Eq. (5) to estimate monthly $\mathrm{CH}_{4}$ emissions from the South Coast Air Basin using the $\mathrm{CH}_{4} / \mathrm{CO}_{2}$ regression slope $R$ determined from CLARS observations and an inventory-based estimate of monthly $\mathrm{CO}_{2}$ emissions (Wong et al., 2015).

$$
\left.E_{\mathrm{CH}_{4}}\right|_{\text {monthly }} ^{\text {top-down }}=\left.R\right|_{\text {monthly }} ^{\text {CLARS }} \times\left. E_{\mathrm{CO}_{2}}\right|_{\text {monthly }} ^{\text {inventory }} \times \frac{\mathrm{MW}_{\mathrm{CH}_{4}}}{\mathrm{MW}_{\mathrm{CO}_{2}}}
$$

However, this requires estimates of the monthly $\mathrm{CO}_{2}$ emissions from the South Coast Air Basin. 


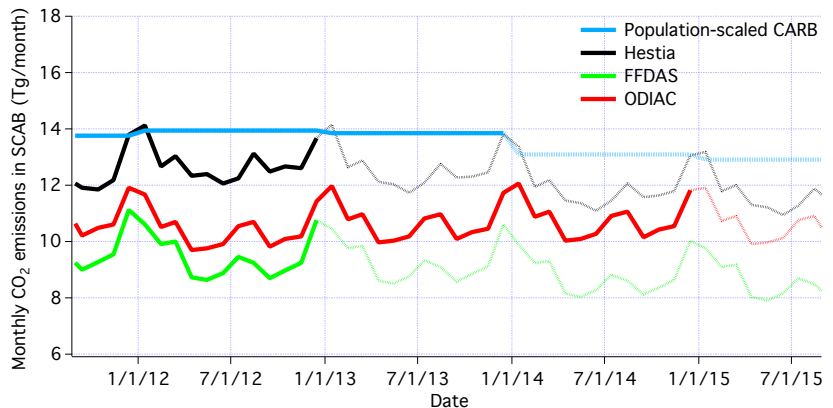

Figure 5. Time series of the different $\mathrm{CO}_{2}$ monthly emissions (in unit of Tg per month) from the South Coast Air Basin. Emissions are color-coded as follows: population-scaled CARB in light blue, Hestia in solid black, ODIAC in solid red, and FFDAS in solid green. Extrapolated emissions using annual fuel consumption data are shown in faded solid lines.

\subsection{Estimating monthly $\mathrm{CO}_{2}$ emissions}

This subsection explores the available $\mathrm{CO}_{2}$ emission database $\left(\left.E_{\mathrm{CO}_{2}}\right|_{\text {monthly }}\right)$ for the basin. CARB reported annual bottom-up statewide $\mathrm{CO}_{2}$ emissions from 2011 to 2013. As described in the results section, we estimated the annual emissions in the South Coast Air Basin by apportioning the statewide emissions using the ratio of population in the South Coast Air Basin to the state population. Because there is no monthly statewide emissions information available, we distributed the annual $\mathrm{CO}_{2}$ emission evenly over 12 months (shown as solid light-blue line in Fig. 5). Data in 2014 and 2015 (shown as faded light-blue line) are extrapolated using statewide annual fuel consumption data provided by the Energy Information Administration (http://www.eia. gov/dnav/ng/hist/n9140us2M.htm; http://www.eia.gov/dnav/ pet $/$ hist/LeafHandler.ash $\mathrm{x}$ n=PET\&s=A103450061\&f=M).

In addition to the official CARB emission inventory, three $\mathrm{CO}_{2}$ emission data products provide monthly temporal resolution for the South Coast Air Basin for our observational period.

1. Hestia. The Hestia fossil fuel $\mathrm{CO}_{2}$ emissions data product provides sectoral bottom-up emissions at the building and street level on hourly timescales (http://hestia. project.asu.edu). Data are available for the South Coast Air Basin for the years 2011 and 2012. Here, we calculated the monthly total $\mathrm{CO}_{2}$ emissions for the South Coast Air Basin domain based on the Hestia $1.3 \mathrm{~km} \times 1.3 \mathrm{~km}$ hourly gridded version 1.0 (shown by the solid black line in Fig. 5). We defined the South Coast Air Basin domain as the rectangular box bounded by $118.83-116.67^{\circ} \mathrm{W}, 33.38-34.77^{\circ} \mathrm{N}$. Because there are no data after 2012, we extrapolated the emissions from 2012 to 2015 (shown as a faded black line in Fig. 5) using the same approach described above.
2. ODIAC. Open-source Data Inventory for Anthropogenic $\mathrm{CO}_{2}$ (ODIAC) provides global emission fields of fossil fuel $\mathrm{CO}_{2}$ emission with $1 \mathrm{~km} \times 1 \mathrm{~km}$ spatial sampling on a monthly basis. ODIAC is based on $\mathrm{CO}_{2}$ emission estimates from the Carbon Dioxide Information and Analysis Center (CDIAC), fuel consumption statistics published by British Petroleum, satellite-observed nightlights and a global power plant database (Oda and Maksyutov, 2011). The monthly $\mathrm{CO}_{2}$ emissions for the South Coast Air Basin domain from September 2011 to December 2014 are shown as the solid red line in Fig. 5. Data in 2015 (shown as the faded red line) are projected using the same approach used to extrapolate the Hestia emissions.

3. FFDAS. Fossil Fuel Data Assimilation System (FFDAS) provides global monthly/hourly sectoral fossil fuel $\mathrm{CO}_{2}$ emission with $0.1^{\circ} \times 0.1^{\circ}$ (approx. $10 \mathrm{~km} \times 10 \mathrm{~km}$ ) spatial sampling (Asefi-Najafabady et al., 2014). This data product is derived from an optimization of the Kaya identity constrained by national fossil fuel $\mathrm{CO}_{2}$ emissions from the International Energy Agency, satellite-observed nightlights, population, and the Ventus power plant dataset. Emissions are available through 2012 (shown as the solid green line). Data from 2013 and onwards (shown as the faded green line) are extrapolated using the same method described previously for CARB, Hestia, and ODIAC.

As shown in Fig. 5, there are differences as large as $3 \mathrm{TgCO}_{2}$ per month among the three gridded datasets: Hestia, ODIAC, and FFDAS. The differences result from (1) emission calculation methods, (2) the underlying dataset used in the emission calculations, and (3) spatial modeling. Hestia is derived primarily from local data in the South Coast Air Basin, while ODIAC and FFDAS are based primarily on national and global proxy approaches. It has been shown that the use of a global dataset may underestimate emissions in Los Angeles by up to $18 \%$ (Brioude et al., 2013). Despite the systematic differences, all three gridded emission datasets show very similar monthly variability, with peaks in summer and winter. Based on the source apportionment in Hestia, the summer peak is due to electricity usage (air conditioning) and the winter peak is due to space heating. In all three datasets, fossil fuel $\mathrm{CO}_{2}$ emissions in the basin show -9 to $+14 \%$ monthly fluctuations about the annual mean.

We believe the Hestia data product provides the most accurate $\mathrm{CO}_{2}$ emission estimates for the South Coast Air Basin among all available databases. Therefore, we used the Hestia $\mathrm{CO}_{2}$ emissions in our calculations to estimate $\mathrm{CH}_{4}$ emissions. We did not use the CARB $\mathrm{CO}_{2}$ emissions in our calculation because the official CARB emission inventories are annual statewide estimates. To derive the monthly $\mathrm{CO}_{2}$ emissions for the basin from the CARB inventory, we have to first scale it to regional emissions by population and then apply the monthly variability from Hestia. Through these steps, we 


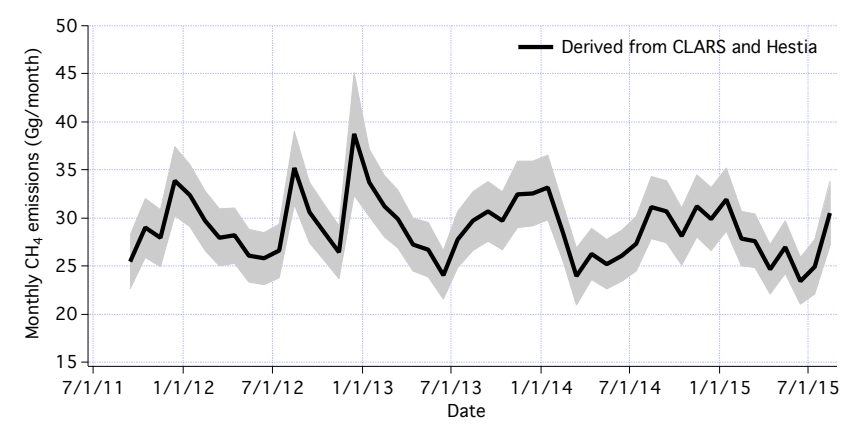

Figure 6. Time series of CLARS-FTS inferred monthly $\mathrm{CH}_{4}$ emissions (in unit of $\mathrm{Gg}$ per month) and their $1 \sigma$ uncertainties from the Los Angeles Basin from September 2011 to August 2015. Overall uncertainties are propagated from the uncertainties in CLARS-FTS $X \mathrm{CH}_{4(X S)}-X \mathrm{CO}_{2(X S)}$ regression slopes and $\mathrm{CO}_{2}$ emissions.

will introduce additional uncertainties in the derived emissions.

\subsection{Deriving top-down monthly $\mathrm{CH}_{4}$ emissions}

This subsection explains the monthly and annual trends of our methane emission estimates.

Figure 6 shows the time series of monthly methane emissions computed from Eq. (6). Shaded areas represent the $1 \sigma$ uncertainties in the derived emissions. Uncertainties are propagated from the uncertainties in CLARS-FTS $X \mathrm{CH}_{4(X S)}-X \mathrm{CO}_{2(X S)}$ regression slopes and $\mathrm{CO}_{2}$ emissions. For $\mathrm{CO}_{2}$ emissions, we assumed a $10 \%$ uncertainty in the Hestia monthly $\mathrm{CO}_{2}$ emissions. The values of the derived monthly methane emissions and their uncertainties can be found in Table S1 of the supplemental material.

Derived methane emission estimates ranged from 23 to $39 \mathrm{Gg} \mathrm{CH}_{4}$ per month. Methane emission peaks occurred in late summer/early fall and winter months. Distinct peaks of methane emission occurred in December 2011, August 2012, and December 2012, when methane emissions exceeded $33 \mathrm{Gg}$ per month. In 2013 and 2014, the summer and fall peaks were less prominent than in 2012. Minimum methane emissions occurred in late spring/early summer when emissions dropped below $27 \mathrm{Gg}$ per month. The monthly variability in methane emissions was -12 to $+16 \%$ in $2011,-13$ to $+31 \%$ in $2012,-19$ to $+14 \%$ in $2013,-16$ to $+17 \%$ in 2014 and -14 to $+17 \%$ in 2015 . Monthly variability reported here is the minimum and maximum percent difference from the annual average. Note that monthly variability in 2011 and 2015 was calculated based on partial annual data, that is, from September to December in 2011 and from January to August in 2015.

Figure 7 plots the monthly patterns of CLARS-FTS inferred methane emissions for each year. The inferred methane emission estimates showed a bimodal distribution with peaks during the winter and the late summer/early fall. The weighted monthly average over this period showed

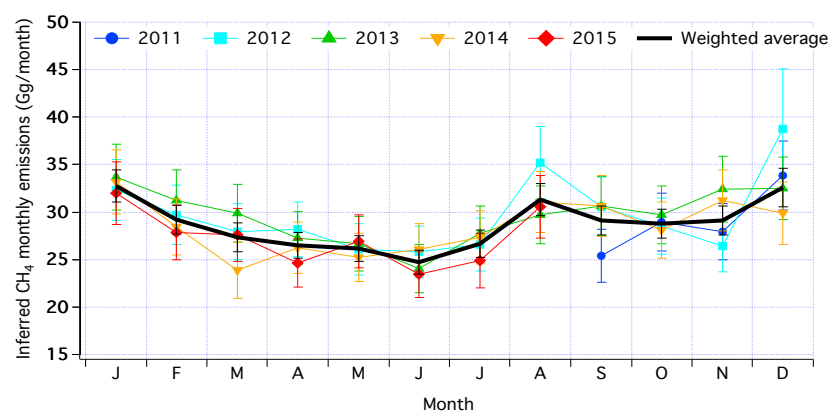

Figure 7. Monthly patterns of derived $\mathrm{CH}_{4}$ emissions (in unit of $\mathrm{Gg}$ per month). Error bars represent the $\pm 1 \sigma$ uncertainties. Derived $\mathrm{CH}_{4}$ emissions are color-coded as follows: 2011 in blue, 2012 in cyan, 2013 in green, 2014 in orange, and 2015 in red. Average monthly emissions and their standard deviations over the entire observational period are shown in black.

maxima in January, August and December at 31, 33, and $32 \mathrm{Gg} \mathrm{CH}_{4}$ per month. The weighted monthly average gradually decreased from January to June, when methane emission reached a minimum of $25 \mathrm{Gg} \mathrm{CH}_{4}$ per month. No statistically significant interannual seasonal variability was observed.

\subsection{Yearly trends in top-down $\mathrm{CH}_{4}$ emissions}

Figure 8 shows the estimated $\mathrm{CH}_{4}$ annual emissions for the South Coast Air Basin from 2011 to 2015. The annual methane emission derived for the South Coast Air Basin was $345 \mathrm{Gg} \mathrm{CH}_{4}$ per year in 2011. Derived emissions increased to $356 \mathrm{Gg} \mathrm{CH}_{4}$ per year in 2013 . Since then, there has been a decreasing trend, reaching $325 \mathrm{Gg} \mathrm{CH}_{4}$ per year in 2015. Due to the large uncertainty propagated mainly from $\mathrm{CO}_{2}$ emissions, we derived a decreasing trend of $-5 \pm 4 \mathrm{Gg} \mathrm{CH}_{4}$ per year with only $25 \%$ confidence level.

Figure 9 compares all reported $\mathrm{CH}_{4}$ annual total emission estimates for the South Coast Air Basin in the past 10 years. These estimates were derived based on in situ ground observations (Hsu et al., 2010), column measurements (Wunch et al., 2009; Wennberg et al., 2012; Wong et al., 2015) and aircraft measurements (Peischl et al., 2013; Wennberg et al., 2012; Wecht et al., 2014; Cui et al., 2015) in the Los Angeles Basin. Among all the previous studies, only one study (Wong et al., 2015) estimated methane emissions for the period between 2011 and 2015. Our estimates for 2011 to 2013 were lower but within uncertainties of the estimates reported by Wong et al. (2015). The difference in the estimated methane emissions between the present study and Wong et al. (2015) is due to differences in the $\mathrm{CO}_{2}$ reference emissions used in the calculations. Hestia $\mathrm{CO}_{2}$ emissions used in the present calculations were lower than the population-scaled CARB emissions used in Wong et al. (2015). The rest of the studies were based on methane observations from 2007 to 2010 . Despite the different study periods, methane emission estimates from our study are in consistent with previous top- 


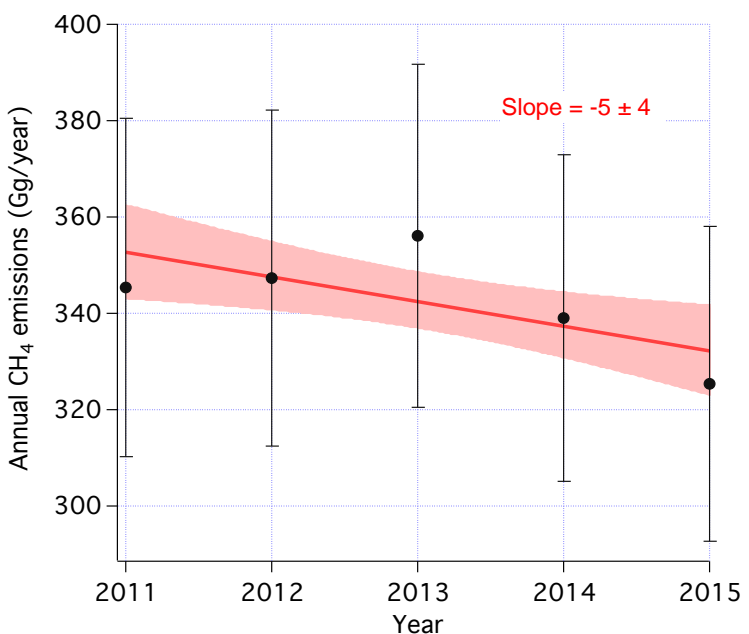

Figure 8. CLARS-FTS inferred annual $\mathrm{CH}_{4}$ emission estimates (in unit of $\mathrm{Gg}$ per month), based on Hestia $\mathrm{CO}_{2}$ emissions. The red line indicates the regression slope and the shaded area is the $25 \%$ confidence interval.

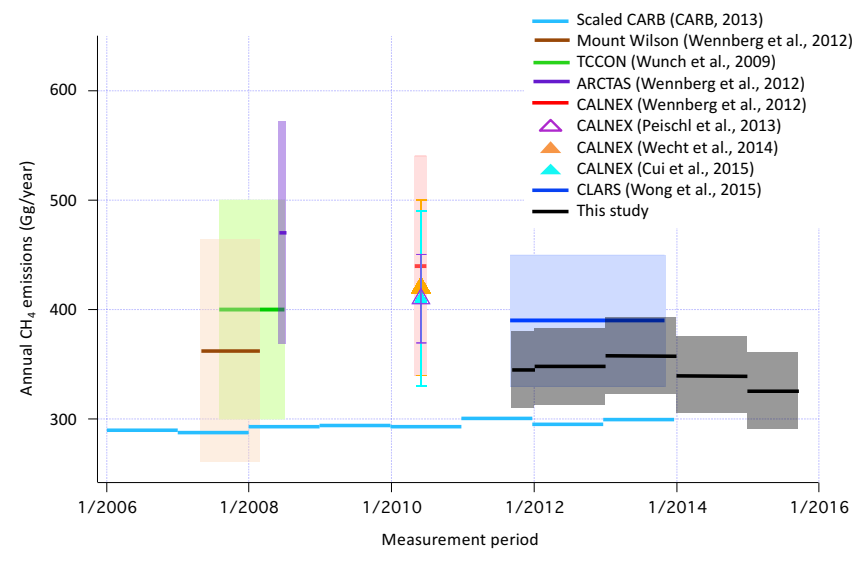

Figure 9. Comparison of annual $\mathrm{CH}_{4}$ emission estimates (in unit of $\mathrm{Gg}$ per month) reported in the past 10 years. The Mount Wilson estimate reported by Wennberg et al. (2012) was derived for the South Coast Air Basin using the emission estimates based on $\mathrm{Hsu}$ et al., 2010.

down estimates. About half of previously reported methane emission estimates were focused on the CALNEX field experiment in May and June 2010. The annual methane emission estimates from these studies could be underestimated as we observed that methane emissions tend to be lowest during these months. When our results are compared to the bottomup inventory, the scaled CARB $\mathrm{CH}_{4}$ emissions from 2011 to 2013 were $2-31 \%$ lower than our estimates.

\subsection{Analysis assumptions}

In this subsection, we discuss the analysis assumptions used to derive $\mathrm{CH}_{4}$ emissions for the South Coast Air Basin using CLARS-FTS observations.

- Spatial and temporal representation based on CLARSFTS measurement technique. We assumed that the CLARS-FTS measurement domain is representative of the South Coast Air Basin. The CLARS-FTS measurement domain covers $67 \%$ of $\mathrm{CO}_{2}$ emissions in the South Coast Air Basin spatial domain according to the Hestia $\mathrm{CO}_{2}$ data product. Therefore, the CLARS-FTS observations are more representative of the sampled area in the South Coast Air Basin than the entire basin. In addition, our methane emission estimates were based on daytime-only observations.

- Spatial and temporal bias due to data filtering. CLARSFTS samples the Los Angeles Basin using its standard measurement sequence. However, as described in Wong et al. (2015), certain months of the year are more prone to cloud and aerosol interference in the Los Angeles Basin. This may introduce biases in the monthly sampling of post-filtered data. The number of post-filtered observations did not have a strong diurnal bias, however. To accurately estimate the Los Angeles Basin value, we used the weighted-average $X \mathrm{CH}_{4(X S)}-X \mathrm{CO}_{2(X S)}$ regression slope, because of the statistical weight for each reflection point is based on the number of samples passing through the data quality filters. We also performed a bootstrap analysis to ensure that there is no sampling bias in the regression slopes (Efron and Tibshirani, 1993).

- Seasonal bias due to transport variability. Changes in meteorology patterns in summer vs. winter can lead to a seasonal dependence on the observations' footprint, which is the sensitivity of the observations to changes in emissions. In the Los Angeles Basin, the prevailing winds are typically northwesterly and onshore throughout the year, except for Santa Ana events (Conil and Hall, 2006). During Santa Ana events, which typically occur during the period from October to March, the wind patterns in the basin shift to easterly and offshore flow (Hughes and Hall, 2010). We investigated the impact of Santa Ana events on our results using the Santa Ana index to remove observations during Santa Ana events (Hughes and Hall, 2010; Conil and Hall, 2006; http://meteora.ucsd.edu/weather/). A correlation analysis showed that applying the Santa Ana index filter did not cause any statistically significant bias on the CLARS monthly $\mathrm{CH}_{4}: \mathrm{CO}_{2}$ ratios. This insensitivity is likely due to the effect of spatial averaging over 28 slant column measurements that span a $50 \mathrm{~km} \times 100 \mathrm{~km}$ spatial domain in the Los Angeles Basin, mitigating the ef- 
fect of transport variability, especially when compared with measurements from individual tower sites. A more diagnostic approach involving the application of a highresolution tracer transport model to investigate potential transport-induced biases on CLARS-FTS results will be carried out in the future.

\subsection{Exploring seasonal variability from major $\mathrm{CH}_{4}$ emission sources}

Currently, there are no monthly-resolved inventories available for us to compare with our top-down results. When these data become available in the future, we hope to better understand the role of each $\mathrm{CH}_{4}$ source in the monthly variability we observed in total $\mathrm{CH}_{4}$ emissions in Los Angeles. In this subsection, we review previous studies of the seasonal emissions variability from major methane sources (landfills, dairies, wastewater treatment plants, and natural gas system leakage) to understand possible contributions to the observed monthly variability in total $\mathrm{CH}_{4}$ emission in the South Coast Air Basin.

- Landfills. Landfills are major emitters of $\mathrm{CH}_{4}$ in the basin. Previous studies suggested that landfills could contribute $41-63 \%$ of total annual methane emissions (Peischl et al., 2013; Wennberg et al., 2012; Hsu et al., 2010). The seasonal variability in landfill $\mathrm{CH}_{4}$ emissions is poorly understood, however. Peischl et al. (2013) estimated the emissions from two of the largest landfills in the basin - Olinda Alpha landfill and Puente Hills landfill - based on aircraft measurements in May and June 2010. Based on observations taken from four flights in May and one flight in June, their studies found that $\mathrm{CH}_{4}$ emissions from Olinda Alpha landfill was almost double in June relative to May, while Puente Hills landfill (which was closed in 2012) showed less than $15 \%$ changes in monthly emissions in 2010. Using a landfill model, Spokas et al. (2015) found that the statewide landfill emissions were largest in October and smallest in April in 2010. Other observational studies found that $\mathrm{CH}_{4}$ emissions from landfills peak in July and August (Shan et al., 2013; Spokas et al., 2011; Tratt et al., 2014; Goldsmith et al., 2012). These studies suggest that landfills can contribute to the late summer/early fall peak in the total $\mathrm{CH}_{4}$ emissions observed by CLARS-FTS but are unlikely to explain the winter peaks.

- Dairies. Previous observations suggested that dairy farms could contribute $32-76 \mathrm{Gg} \mathrm{CH}_{4}$ per year in the South Coast Air Basin (Peischl et al., 2013; Wennberg et al., 2012). This corresponds to 8 to $36 \%$ of the reported total annual $\mathrm{CH}_{4}$ emissions in the studies. In general, studies on dairies focus on mitigation strategies rather than quantifying temporal changes in emissions. Limited studies of dairy emissions report peaks in $\mathrm{CH}_{4}$ emissions in summer and early fall (from June to September) and steady minima in spring and winter (VanderZaag et al., 2009, 2010, 2013, 2014; Ulyatt et al., 2002; Kaharabata et al., 1998). These findings imply that dairies can also be contributing to the summer/early fall peaks in the CLARS-FTS inferred $\mathrm{CH}_{4}$ emissions.

- Wastewater treatment. This sector is suggested to be responsible for $33 \%$ of Los Angeles County and $9.4 \%$ of the South Coast Air Basin (Hsu et al., 2010; Wennberg et al., 2012). Daelman et al. (2012, 2013) measured $\mathrm{CH}_{4}$ emissions from a wastewater treatment facility for 1 year (2010-2011) and reported up to $40 \%$ monthly fluctuations from the mean, with a maximum in June.

- Fossil fuel sources. Recent studies based on mobile, stationary, and airborne measurements of methane in Los Angeles have indicated that fossil fuel sources contribute 47 to $90 \%$ of the total $\mathrm{CH}_{4}$ emissions in the basin (Wennberg et al., 2012; Townsend-Small et al., 2012; Peischl et al., 2013; Hopkins et al., 2016). Wennberg et al. (2012) and Peischl et al. (2013) suggested that fugitive emission from natural gas distribution system leakage contributes to the gaps between bottom-up and topdown total $\mathrm{CH}_{4}$ emissions in the South Coast Air Basin. McKain et al. (2014) found little seasonal dependence $(<10 \%)$ on the emissions from the natural gas system in Boston, Massachusetts. Their studies showed a leakage rate of $2.7 \pm 0.6 \%$ from the natural gas system. Wennberg et al. (2012) reported a consistent leakage rate from the natural gas system in Los Angeles and suggested that most of the leakages from such systems are likely to occur in residential/commercial areas where the distribution system ends. Publicly available natural gas consumption data from residential and commercial sectors in the South Coast Air Basin show a significant seasonal cycle with a maximum in winter due to heating (https://energydatarequest.socalgas.com/). Wennberg et al. (2012) and McKain et al. (2014) observed that the leakage rate from the natural gas system is constant throughout the year and suggested that the majority of leakage occurs in the distribution system to the residential and commercial sectors. This conclusion is reasonable since the natural gas distribution pipeline system is pressure-regulated at several points, and leakage should be independent of consumption to first order. However, this is not the case for natural gas storage facilities, which are pressurized to higher levels in the summer and late fall in Southern California to respond to increased demands for summertime electric power generation for air conditioning and wintertime space heating. In October 2015, a massive leak began at an underground well pipe at the Aliso Canyon (Los Angeles) natural gas storage facility as it was being pressurized to provide wintertime reserves. While this leak was unprecedented in scale, it raises the question of whether 
smaller fugitive leaks in the storage infrastructure from this and numerous other above- and belowground reservoirs contribute to the seasonal variability observed in CLARS-FTS data. The Aliso Canyon leak resulted in very large increases (as much as a factor of 10) in the observed instantaneous values of $X \mathrm{CH}_{4(X S)} / \mathrm{XCO}_{2(X S)}$ throughout the entire CLARS-FTS field of regard. Since CLARS-FTS is capable of resolving $\mathrm{CH}_{4}$ enhancements that are significantly smaller than those caused by the Aliso Canyon leak, perhaps seasonally varying fugitive emissions from natural gas storage facilities and associated infrastructure are partially responsible for the observed monthly variability. Enhanced long-term monitoring for fugitive emissions will be required to test this hypothesis.

\section{Summary and conclusions}

Using CLARS-FTS mountaintop remote sensing observations from Mount Wilson along with tracer-tracer $\mathrm{CH}_{4}: \mathrm{CO}_{2}$ correlation analyses, we estimated the monthly variability in $\mathrm{CH}_{4}: \mathrm{CO}_{2}$ and top-down $\mathrm{CH}_{4}$ emissions from the South Coast Air Basin from 2011 to 2015. Significant monthly variability $(-18$ to $+22 \%)$ in $\mathrm{CH}_{4}: \mathrm{CO}_{2}$ was observed. Double peaks in late summer/early fall and winter occurred consistently during the study period. The fall peak in the $\mathrm{CH}_{4}: \mathrm{CO}_{2}$ ratios was also observed by TCCON (Wennberg et al., 2012). The CLARS-FTS $X \mathrm{CH}_{4(X S)}-X \mathrm{CO}_{2(X S)}$ regression slopes showed -7 to $10 \%$ year-to-year seasonal variability, with an increasing trend in the fall season from 2012 to 2014. The annual average $X \mathrm{CH}_{4(X S)}-X \mathrm{CO}_{2(X S)}$ regression slopes showed less than $4 \%$ year-to-year variability between 2011 and 2015.

Using the best available estimates of $\mathrm{CO}_{2}$ emissions, topdown estimates of $\mathrm{CH}_{4}$ emissions were determined using the emission ratio method. Repeatable peaks in late summer/early fall and winter were observed between 2011 and 2015. There were significant monthly fluctuations $(-19$ to $+31 \%$ from annual mean and a maximum month-to-month change of $47 \%$ ) in the inferred methane emissions in the basin. Based on previous studies on the seasonal variability in $\mathrm{CH}_{4}$ emissions from $\mathrm{CH}_{4}$ sources, we concluded that landfills, dairies, and wastewater treatment facilities are likely sources of the peak $\mathrm{CH}_{4}$ emissions in late summer/early fall. Fugitive emissions from natural gas storage facilities and associated infrastructure may contribute to both the late summer and late fall peaks.

No significant trend in $\mathrm{CH}_{4}$ emissions $\left(-5 \pm 4 \mathrm{Gg} \mathrm{CH}_{4}\right.$ per year with a $25 \%$ confidence level due to the uncertainty in $\mathrm{CO}_{2}$ emissions) could be discerned over the 2011 to 2015 time period. The population-scaled bottom-up $\mathrm{CH}_{4}$ emissions from 2011 to 2013 were $2-31 \%$ lower than our topdown estimates. These results are consistent with previous studies (Wunch et al., 2009; Hsu et al., 2010; Wennberg et al., 2012; Peischl et al., 2013; Wong et al., 2015). A combination of several measurement and modeling strategies are necessary to further disentangle the monthly variability in methane sources in the Los Angeles Basin.

\section{Data availability}

The CLARS-FTS measurements are available upon request. A portion of the data are available on the Megacities Carbon Project data portal (https://megacities.jpl.nasa.gov/portal).

\section{The Supplement related to this article is available online at doi:10.5194/acp-16-13121-2016-supplement.}

Acknowledgements. The research in this study was performed at the Jet Propulsion Laboratory, California Institute of Technology, under a contract with the National Aeronautics and Space Administration. Clare K. Wong thanks the California Air Resources Board, NIST GHG and Climate Science Program, and the W. M. Keck Institute for Space Studies for support. The authors would like to acknowledge our colleagues at JPL and California Institute of Technology, and Risa Patarasuk at Arizona State University for helpful comments and suggestions.

Edited by: R. Harley

Reviewed by: two anonymous referees

\section{References}

Asefi-Najafabady, S., Rayner, P. J., Gurney, K. R., McRobert, A., Song, Y., Coltin, K., Huang, J., Elvidge, C., and Baugh, K.: A multiyear, global gridded fossil fuel $\mathrm{CO}_{2}$ emission data product: Evaluation and analysis of results, J. Geophys. Res.-Atmos., 118, 1-19, doi:10.1002/2013JD021296, 2014.

Brioude, J., Angevine, W. M., Ahmadov, R., Kim, S.-W., Evan, S., McKeen, S. A., Hsie, E.-Y., Frost, G. J., Neuman, J. A., Pollack, I. B., Peischl, J., Ryerson, T. B., Holloway, J., Brown, S. S., Nowak, J. B., Roberts, J. M., Wofsy, S. C., Santoni, G. W., Oda, T., and Trainer, M.: Top-down estimate of surface flux in the Los Angeles Basin using a mesoscale inverse modeling technique: assessing anthropogenic emissions of $\mathrm{CO}, \mathrm{NO}_{x}$ and $\mathrm{CO}_{2}$ and their impacts, Atmos. Chem. Phys., 13, 3661-3677, doi:10.5194/acp13-3661-2013, 2013.

California Air Resources Board: Greenhouse gas emission inventory - Query tool for years 2000 to 2013, 8th Edn., http: //www.arb.ca.gov/app/ghg/2000_2013/ghg_sector.php, (last access: January 2015), 2013.

Conil, S. and Hall, A.: Local regimes of Atmospheric Variability: A case study of Southern California, J. Climate, 19, 4308, 2006.

Cui, Y. Y., Brioude, J., McKeen, S. A., Angevine, W. M., Kim, S.W., Frost, G. J., Ahmadov, R., Peischl, J., Bousserez, N., Liu, Z., Ryerson, T. B., Wofsy, S. C., Santoni, G. W., Kort, E. A., Fischer, M. L., and Trainer, M.: Top-down estimate of methane 
emissions in California using a mesoscale inverse modeling technique: The South Coast Air Basin, J. Geophys. Res.-Atmos., 120, 6698-6711, 2015.

Daelman, M. R., van Voorthuizen, E. M., van Dongen, U. G., Volcke, E. I., and van Loosdrecht, M. C.: Methane emission during municipal wastewater treatment, Water Res., 46, 3657-3670, 2012.

Daelman, M. R., van Voorthuizen, E. M., van Dongen, L. G., Volcke, E. I., and van Loosdrecht, M. C.: Methane and nitrous oxide emissions from municipal wastewater treatment - results from a long-term study, Water Sci. Technol., 67, 2350-2355, 2013.

Efron, B. and Tibshirani, R.: An Introduction to the Bootstrap, CRC press, Boca Raton, Florida, USA, 57, 45-82, 1993.

Fu, D., Pongetti, T. J., Blavier, J.-F. L., Crawford, T. J., Manatt, K. S., Toon, G. C., Wong, K. W., and Sander, S. P.: Near-infrared remote sensing of Los Angeles trace gas distributions from a mountaintop site, Atmos. Meas. Tech., 7, 713-729, doi:10.5194/amt7-713-2014, 2014.

Goldsmith, C. D., Chanton J., Abichou T., Swan, N., Green, R., and Haters, G.: Methane emissions from 20 landfills across the United States using vertical radial plume mapping, Air Waste Manage., 62, 183-197, 2012.

Hopkins, F. M., Kort, E. A., Bush, S. E., Ehleringer, J. R., Lai, C.T., Blake, D. R., and Randerson, J. T.: Spatial patterns and source attribution of urban methane in the Los Angeles Basin, JGR-A, 121, 2490-2507, 2016.

Hsu, Y.-K., VanCuren, T., Park, S., Jakober, C., Herner, J., FitzGibbon, M., Blake, D., and Parrish, D. D.: Methane emissions inventory verification in southern California, Atmos. Environ., 44, $1-7,2010$.

Hughes, M. and Hall, A.: Local and synoptic mechanisms causing Southern California's Santa Ana winds, Clim. Dynam., 34, 847$857,2010$.

Jeong, S., Hsu, Y.-K., Andrews, A. E., Bianco, L., Vaca, P., Wilczak, J. M., and Fischer, M. L.: A multitower measurement network estimate of California's methane emissions, J. Geophys. Res.Atmos., 118, 11339-11351, 2013.

Kaharabata, S. K., Schuepp, P. H., and Desjardins, R. L.: Methane emissions from above ground open manure slurry tanks, Global Biogeochem. Cy., 12, 545-554, 1998.

Mckain, K., Down, A., Raciti, S. M., Budney, J., Hutyra, L. R., and Floerchinger, C.: Methane emissions from natural gas infrastructure and use in the urban region of Boston, Massachusetts, P. Natl. Acad. Sci. USA, 112, 1941-1946, 2014.

Oda, T. and Maksyutov, S.: A very high-resolution $(1 \mathrm{~km} \times 1 \mathrm{~km})$ global fossil fuel $\mathrm{CO}_{2}$ emission inventory derived using a point source database and satellite observations of nighttime lights, Atmos. Chem. Phys., 11, 543-556, doi:10.5194/acp-11-543-2011, 2011.

Peischl, J., Ryerson, T. B., Brioude, J., Aikin, K. C., Andrews, A. E., Atlas, E., Blake, D., Daube, B. C., de Gouw, J. A., Dlugokencky, E., Frost, G. J., Gentner, D. R., Gilman, J. B., Goldstein, A. H., Harley, R. A., Holloway, J. S., Kofler, J., Kuster, W. C., Lang, P. M., Novelli, P. C., Santoni, G. W., Trainer, M., Wofsy, S. C., and Parrish, D. D.: Quantifying sources of methane using light alkanes in the Los Angeles basin, California, J. Geophys. Res.Atmos., 118, 4974-4990, doi:10.1002/jgrd.50413, 2013.

Shan, J., Iacoboni, M., and Ferrante, R.: Estimating greenhouse gas emissions from three Southern California landfill sites, Proceed- ings of SWANA's 2013 Landfill Gas Symposium, Silver Springs, MD, 2013.

Spokas, K., Bogner, J., and Chanton, J.: A process-based inventory model for landfill $\mathrm{CH}_{4}$ emissions inclusive of seasonal soil microclimate and $\mathrm{CH}_{4}$ oxidation, J. Geophys. Res., 116, G04017, doi:10.1029/2011JG001741, 2011.

Spokas, K., Bogner, J., Corcoran, M., and Walker, S.: From California dreaming to California data: Challenging historic models for landfill $\mathrm{CH}_{4}$ emissions, Elementa, doi:10.12952/journal.elementa.000051, 2015.

Tratt, D. M., Buckland, K. N., Hall, J. L., Johnson, P. D., Keim, E. R., Leifer, I., Westberg, K., and Young, S. J.: Airborne visualization and quantification of discrete methane sources in the environment, Remote Sens. Environ., 154, 74-88, 2014.

Townsend-Small, A., Tyler, S. C., Pataki, D. E., Xu, X., and Christensen, L. E.: Isotopic measurements of atmospheric methane in Los Angeles, California, USA: Influence of "fugutive" fossil fuel emissions, J. Geophys. Res.-Atmos., 117, 1-11, doi:10.1029/2011JD016826, 2012.

Ulyatt, M. J., Lassey, K. R., Shelton, I. D., and Walker, C. F.: Seasonal variation in methane emission from dairy cows and breeding ewes grazing ryegrass/white clover pasture in New Zealand, New Zeal. J. Agr. Res., 45, 227-234, 2002.

VanderZaag, A. C., Gordon, R. J., Jamieson, R. C., Burton, D. L., and Stratton, G. W.: Gas emissions from straw covered liquid dairy manure during summer storage and autumn agitation, Trans. Am. Soc. Agric. Eng., 52, 599-608, 2009.

VanderZaag, A. C., Gordon, R. J., Jamieson, R. C., Burton, D. L., and Stratton, G. W.: Effects of winter storage conditions and subsequent agitation on gaseous emissions from liquid dairy manure, Can. J. Soil. Sci., 90, 229-239, 2010.

VanderZaag, A. C., Flesch, T. K., Desjardins, R. L., Baldé, H., and Wright, T.: Measuring methane emissions from two dairy farms: Seasonal and manure-management effects, Agr. Forest Meteorol., 194, 259-267, 2014.

VanderZaag, A. C., MacDonald, J. D., Evans, L., Vergé, X. P., and Desjardins, R. L.: Towards an inventory of methane emissions from manure management that is responsive to changes on Canadian farms, Environ. Res. Lett., 8, 035008, doi:10.1088/17489326/8/3/035008, 2013.

Wecht, K. J., Jacob, D. J., Sulprizio, M. P., Santoni, G. W., Wofsy, S. C., Parker, R., Bösch, H., and Worden, J.: Spatially resolving methane emissions in California: constraints from the CalNex aircraft campaign and from present (GOSAT, TES) and future (TROPOMI, geostationary) satellite observations, Atmos. Chem. Phys., 14, 8173-8184, doi:10.5194/acp-14-8173-2014, 2014.

Wennberg, P. O., Mui, W., Wunch, D., Kort, E. A., Blake, D. R., Atlas, E. L., Santoni, G. W., Wofsy, S. C., Diskin, G. S., Jeong, S., and Fischer, M. L.: On the sources of methane to the Los Angeles atmosphere, Environ. Sci. Technol., 46, 9282-9289, 2012.

Wong, K. W., Fu, D., Pongetti, T. J., Newman, S., Kort, E. A., Duren, R., Hsu, Y.-K., Miller, C. E., Yung, Y. L., and Sander, S. P.: Mapping $\mathrm{CH}_{4}$ : $\mathrm{CO}_{2}$ ratios in Los Angeles with CLARSFTS from Mount Wilson, California, Atmos. Chem. Phys., 15, 241-252, doi:10.5194/acp-15-241-2015, 2015.

Wunch, D., Wennberg, P. O., Toon, G. C., Keppel-Aleks, G., and Yavin, Y. G.: Emissions of greenhouse gases from a North American megacity, Geophys. Res. Lett., 36, 1-5, 2009. 